\title{
Potencial ecológico para o manejo de frutos de açaizeiro (Euterpe precatoria Mart.) em áreas extrativistas no Acre, Brasil.
}

\author{
Elektra ROCHA ${ }^{1}$
}

\begin{abstract}
RESUMO
Uma das espécies potenciais para a diversificação da produção florestal não-madeireira é Euterpe precatoria Mart., cujo manejo de seus frutos para produção de polpa engloba aspectos sociais, econômicos e ecológicos concernentes à floresta. No presente estudo analisamos a densidade, estrutura, dinâmica e a estabilidade populacional desta espécie em florestas inundadas e de terra firme para avaliar o potencial ecológico de manejo. A densidade média de adultos na floresta de baixio foi de 60 indivíduos ha ${ }^{-1}$ e na terra firme de 23 indivíduos ha ${ }^{-1}$. A estrutura populacional apresentou-se em forma de $\mathrm{J}$ invertido. Houve uma alta produção de frutos e a sua produção por indivíduo não foi diferente entre os tipos florestais. A estabilidade populacional apresentou-se variável entre os tipos florestais e os sítios amostrados. Este estudo sugere que de modo geral Euterpe precatoria possui características ecológicas favoráveis para seu manejo sustentável, tais como alta densidade e freqüência, regeneração abundante e grande produção de frutos. Um maior potencial de manejo apresentouse na floresta de baixio comparado ao da terra firme.
\end{abstract}

\section{PALAVRAS-CHAVE}

Floresta tropical; Amazônia ocidental; Palmeira; Estrutura populacional; Potencial de manejo.

\section{Ecologic potential for the management of açaizeiro fruits (Euterpe precatoria Mart.) in extractive areas in Acre, Brazil.}

\begin{abstract}
One of the species with a diversification potential for non-timber forest products is Euterpe precatoria Mart., whose fruit management for pulp production includes social, economical and ecological aspects. This study analyzes the density, structure, dynamics and stability of a population Euterpe precatoria in terra firme and inundated forests to evaluate the ecological potential of management. The mean adult density in inundated forests was 60 individuals ha $a^{-1}$ and 23 individuals $\mathrm{ba}^{-1}$ in terra firme forest. Population structure showed an inverse J shape. There was a bigh fruit production and the population stability was variable among the study sites. These ecological characteristics suggest that this species has a bigh management potential, such as high density and frequency, abundant regeneration and high fruit production. A greater management potential was observed in inundated forests when compared with terra firme.
\end{abstract}

\section{KEY WORDS}

Tropical forest; Western Amazonia; Palm; Population structure; Management potential.

\section{INTRODUÇÃO}

Os seringueiros na Amazônia Ocidental possuem como meio econômico principalmente o extrativismo de borracha e castanha. Porém, eles têm se interessado pela diversificação de seus produtos com outros recursos florestais para complementar sua renda, respeitando tanto os seus modos tradicionais de vida quanto a biodiversidade.
Em 1990 o valor de exportação de produtos florestais não madeireiros (PFNM) foi de U\$11 milhões para o Peru, U\$14 milhões para o Equador, U\$22 milhões para a Bolívia e U\$52 milhões para o Brasil (Broekhoven 1995, citado por Ros-Tonen, et al. 1995).

Na Amazônia brasileira, em 1998 as exportações de produtos não madeireiros foram de aproximadamente $\mathrm{U} \$ 44$ milhões, o que corresponde a $6 \%$ da produção florestal e agropecuária da região (SECEX, 1998).

\footnotetext{
${ }^{1}$ Laboratório de Silvicultura Tropical - Escola Superior de Agricultura Luis de Queiroz (USP). Av. Pádua Dias, 11. Caixa Postal 9, CEP: 13418900.
} Piracicaba, São Paulo 


\section{ACTA \\ AMAZONICA}

POTENCIAL ECOLÓGICO PARA O MANEJO DE FRUTOS DE AÇAIZEIRO

(Euterpe precatoria MART.) EM ÁREAS EXTRATIVISTAS NO ACRE, BRASIL
Uma das espécies com potencial de extração é o açaizeiro (Euterpe precatoria Mart.), do qual é extraída a polpa de seus frutos, um produto importante para a diversificação da produção florestal de algumas comunidades extrativistas, (1) por serem coletados e utilizados pelos seringueiros desde a expansão da borracha (Fearnside, 1992), (2) por terem grande potencial econômico (Kahn, 1993), e (3) por agregar valores nos mercados locais e regionais e mais recentemente no nacional.

O manejo de frutos do açaizeiro implica em práticas utilizando métodos científicos e /ou tradicionais habituais (Neumann \& Hirsch, 2000) para aumentar a produtividade das áreas de florestas. Esta iniciativa pode gerar empregos, distribuição de renda, baixo impacto sócio-ambiental pelo uso de um recurso florestal comercialmente valioso, e ainda, aumentar do valor da floresta em pé. Mas para que esta prática seja sustentável ao longo do tempo, torna-se necessário obter algumas informações ecológicas para avaliar o potencial de manejo deste produto.

Embora haja evidências consideráveis da colheita excessiva de PFNM, estão faltando análises quantitativas do potencial de manejo dos frutos do açaizeiro: Sem tais análises, não é possível avaliar o efeito da colheita do recurso em comunidades naturais, nem é possível projetar planos de manejo apropriados para a conservação.

Considerando-se que (1) o potencial de manejo do açaizeiro depende de suas características botânicas, ciclo de vida e produtividade (Peters, 1996) e (2) a alta heterogeneidade de tipologias florestais da Amazônia ocidental, os objetivos aqui foram: (1) avaliar a densidade de açaizeiro em florestas de terra firme e baixio no Vale do Rio Acre; (2) Determinar a distribuição da população em classes de tamanho em condições de baixio e terra firme no Vale do Rio Acre; (3) Estimar a estabilidade das populações de E. precatoria nas áreas estudadas; (4) Estimar a produção de frutos do Açaí nas duas tipologias florestais em questão.

\section{MATERIAL E MÉTODOS}

\section{Áreas de estudo}

Este estudo foi conduzido na Reserva Extrativista Chico Mendes e no Seringal Caquetá, ambos no Vale do Rio Acre, Estado do Acre, Brasil.

A Reserva Extrativista Chico Mendes $\left(10^{\circ} 05^{\prime} 41^{\prime \prime S ~ e ~} 68^{\circ}\right.$ $30^{\prime} 10^{\prime \prime}$ W) está localizada nos municípios de Assis Brasil, Brasiléia, Xapuri, Sena Madureira e Rio Branco, com aproximadamente um milhão de hectares. As áreas de estudo nesta reserva estão localizadas no Seringal Dois Irmãos, (1) sítio Já Começa, Município de Xapuri e no Seringal Porongaba, (2) sítio Santa Maria, Município de Brasiléia, AC (Tabela 1).

O Seringal Caquetá $\left(09^{\circ} 33^{\prime} 50^{\prime \prime} \mathrm{S}\right.$ e $\left.67^{\circ} 19^{\prime} 40^{\prime \prime} \mathrm{W}\right)$ no município de Porto Acre, com uma área de cerca de 30.000 ha (INCRA, 1997). As áreas de estudo neste seringal estão localizadas nos sítios (3) São Pedro, (4) Arraia, (5) Limoeiro e (6) Morada Nova, Município de Porto Acre, AC (Tabela 1).

A região apresenta uma temperatura média anual de 23 ${ }^{\circ} \mathrm{C}$ variando de $17{ }^{\circ} \mathrm{C}$ (período mais frio) a $38{ }^{\circ} \mathrm{C}$ (período mais quente). A precipitação de chuvas anual é em torno de $2000 \mathrm{~mm}$ variando de $850 \mathrm{~mm}$ (janeiro a março) a $150 \mathrm{~mm}$ (julho a setembro) (Governo do Estado do Acre, 2000).

Os tipos principais de solos que ocorrem no estado do Acre são: Argissolos, Cambissolos, Gley e Latossolo (Radam Brasil, 1976).

A vegetação é classificada como Floresta Ombrófila Aberta das Terras Baixas com Cipó, Bambu ou Palmeira, inserida dentro de um bioclima de 30 a 90 dias secos (Veloso et al., 1991; IBGE, 1993). Em todas as áreas deste estudo pode-se reconhecer tipologias florestais distintas, entre elas, as florestas chamadas de baixio e de terra firme.

Os baixios são definidos aqui como florestas que inundam sazonalmente no período de novembro - março e/ou que sofrem influência direta dos igarapés. Estas florestas, devido à topografia possuem lençol freático mais superficial, que em épocas chuvosas, aflora e inunda estas áreas. Apresentam dossel mais aberto em relação às florestas de terra firme (Lamotte, 1990), pela predominância de palmeiras arborescentes e uma grande abundância de palmeiras de subosque. O período de inundação das florestas de baixio nas áreas de estudo dura de 4 a 5 meses por ano.

As florestas de terra firme cobrem planaltos e florestas de encosta e são áreas com dossel mais fechado, solos bem drenados em qualquer época do ano, e que não são inundadas por rios e fluxos pequenos de água. Estas florestas são dominadas por árvores grandes e caracterizam-se por estrutura vertical bem desenvolvida e diversidade de espécies arbóreas muito alta (Prance et al., 1976) em relação às florestas sazonalmente inundadas (Kahn \& De Granville, 1992).

\section{DESCRIÇÃO DA ESPÉCIE}

Euterpe precatoria Mart. é uma palmeira neotropical de subdossel que possui um estipe único, cinza claro. A espécie tem distribuição desde a América Central (Belize, Guatemala, Honduras, Nicaragua, Costa Rica e Panamá) até o norte da América do Sul (Colômbia, Venezuela, Trinidad, Guianas, Equador, Peru, Brasil e Bolívia). No Brasil a palmeira ocorre nos estados amazônicos do Acre, Amazonas, Rondônia e Pará (Henderson, 1995).

Possui raízes adventícias continuamente na base do estipe, nas quais formam um anel espesso, de raízes aéreas $(1.5 \mathrm{~cm})$ purpúreas que pode alcançar $80 \mathrm{~cm}$ do nível do solo (Castro \& Bovi, 1993).

As inflorescências bissexuais se desenvolvem na axila das folhas, depois da senescência da folha mais velha e são protegidas por estruturas denominadas ferófilos. Euterpe precatoria parece ser uma palmeira geralmente entomófila (Küchmeister et al., 1997). 


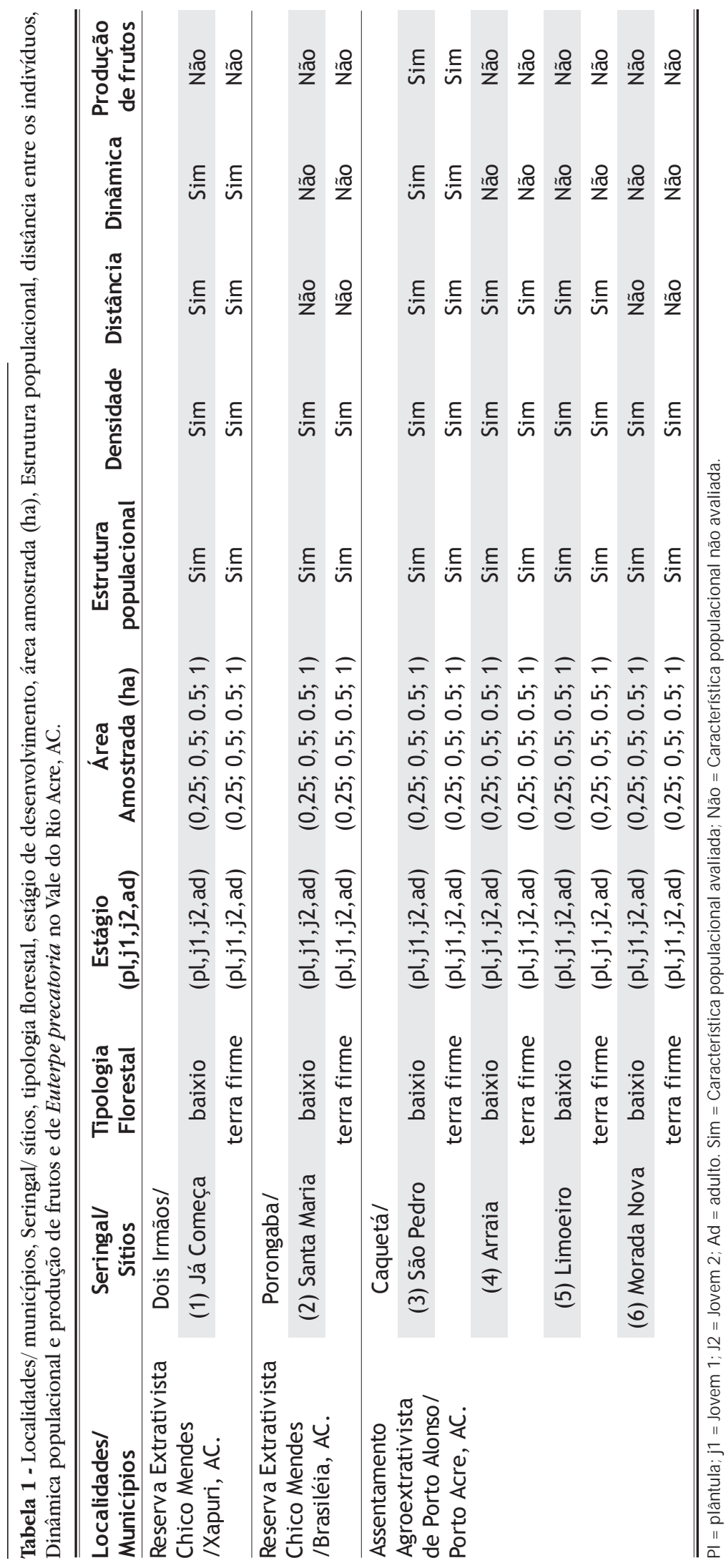

Os frutos são globosos, púrpura-escuro quando maduros, com mesocarpo suculento. Há uma semente por fruto, com endosperma sólido e homogêneo (Henderson, 1995).

\section{Estrutura, densidade, distância e dinâmica populacional de Euterpe precatoria.}

O método utilizado para avaliar a estrutura populacional, densidade e a dinâmica da população foi o de transectos.

Para estudar a estrutura populacional de Euterpe precatoria os indivíduos foram divididos em quatro estágios do desenvolvimento segundo o tamanho e caracteres vegetativos/reprodutivos a saber:

(1) Plântulas: indivíduos abaixo de $50 \mathrm{~cm}$ de altura;

(2) Jovem 1: indivíduos acima de $50 \mathrm{~cm}$ de altura, que não possuem estipe aparente;

3) Jovem 2: indivíduos com estipe aparente (desprovida de bainha), nãoreprodutivos;

4) Adultos: indivíduos reprodutivos (aqueles que possuem ferófilos aparentes, cachos novos e/ou restos de cachos velhos, na planta ou no solo debaixo do indivíduo).

Em cada sítio foram abertos dois transectos de 500 × 20 metros (um na floresta de baixio, outro na floresta de terra firme) com localização restrita-aleatória (Matteucci \& Colma, 1982). Os transectos foram divididos em 20 parcelas de $500 \mathrm{~m}^{2}$ para a contagem de indivíduos adultos, 20 parcelas de $250 \mathrm{~m}^{2}$ para a contagem de jovens 1 e 2 e 20 parcelas de $125 \mathrm{~m}^{2}$ para a contagem de plântulas, totalizando $1,0,5$ e 0,25 ha respectivamente para cada floresta de baixio e de terra firme (Tabela 1 e Figura 1).

Para estimar a densidade média do açaizeiro em terra firme e baixio no Vale do Rio Acre foi utilizado um total de seis parcelas de 1 hectare para a amostragem de adultos, seis parcelas de 0,5 hectare para jovens 1 e 2 e seis parcelas de 0,25 hectare para plântulas (Tabela 1). A freqüência (presença de indivíduos nas amostragens) do açaizeiro também foi avaliada no Vale do Rio Acre.

Dentro dos transectos nas florestas de baixio e de terra firme de 4 sítios (Tabela 1) foram calculadas as distâncias médias entre os indivíduos de um mesmo estágio de desenvolvimento. 


\section{ACTA \\ AMAZONICA}

POTENCIAL ECOLÓGICO PARA O MANEJO DE FRUTOS DE AÇAIZEIRO

(Euterpe precatoria MART.) EM ÁREAS EXTRATIVISTAS NO ACRE, BRASIL

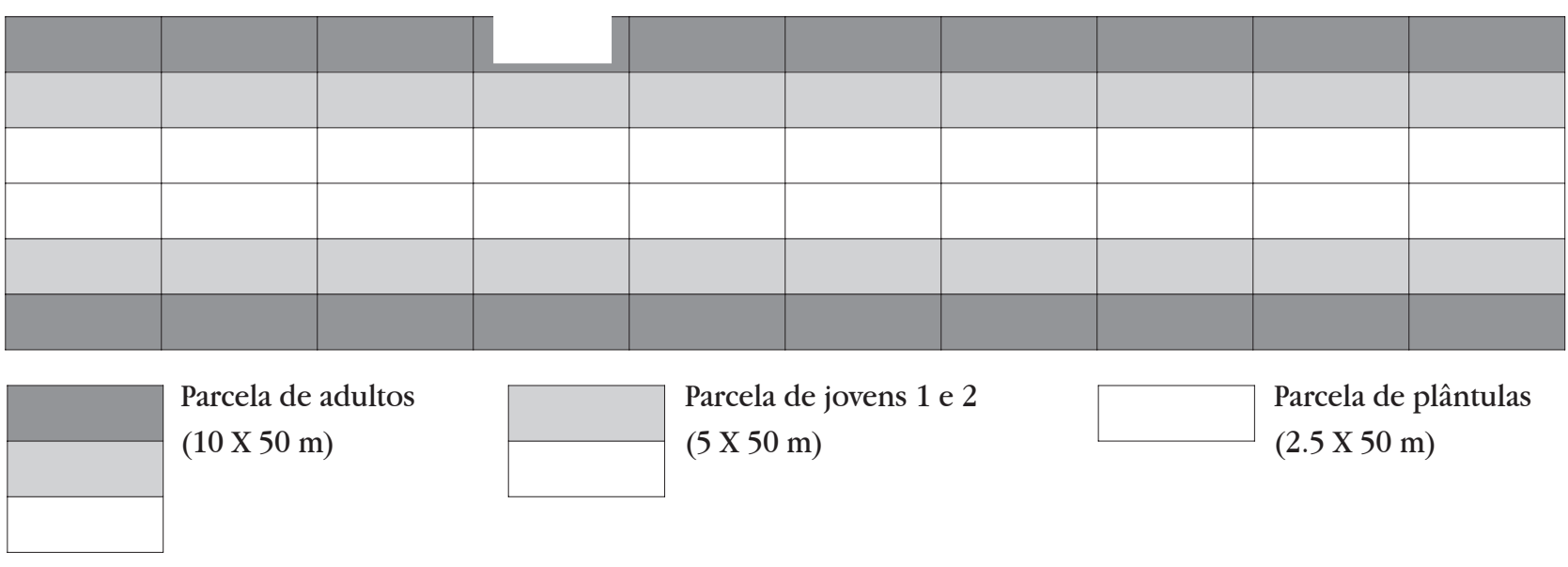

Figura 1 - Croqui dos transectos em áreas de baixio e terra Firme, AC (sem escala). Transecto dividido em 20 parcelas de $500 \mathrm{~m}^{2}$ para contagem de adultos, 20 parcelas de $250 \mathrm{~m}^{2}$ para a contagem de jovens e 20 parcelas de $125 \mathrm{~m}^{2}$ para a contagem de plântulas.

Para calcular a distância entre indivíduos, considerouse que sua distribuição seja uniforme na área. Ela foi calculada a partir da formula:

$$
D=\sqrt{ }(A * 4 / \pi)
$$

Este cálculo é uma aplicação inversa dos cálculos utilizados no método de quadrantes (Cottam \& Curtis, 1956).

O método de transecto facilitou delimitar os diferentes tipos florestais, otimizou o tempo e dinheiro. Estes aspectos são fundamentais para se fazer à avaliação do potencial produtivo de produtos florestais não madeireiros, mesmo considerando as limitações estatísticas do método (Hubbel, 1984; Mateucci-Colma, 1982).

Os dados sobre a dinâmica da população foram coletados no sítio Já Começa e São Pedro em florestas de baixio e de terra firme (Tabela 1) utilizando o método descrito para a avaliação da estrutura populacional. Foram feitas duas observações no período de um ano. Todos os indivíduos adultos e jovens 2 foram marcados com plaquetas de alumínio e prego, enquanto as plântulas e jovens 1 com plaquetas de alumínio e arame. Após o período de 1 ano foi feito o recenseamento nas duas áreas, onde foram levantados dados demográficos de sobrevivência, transição e fecundidade na floresta de baixio e de terra firme.

A taxa anual de sobrevivência $\left(\sigma_{\mathrm{i}}\right)$ de palmeiras na classe de tamanho i foi calculada como o número de palmeiras que sobreviveram durante aquele ano $\left(\mathrm{S}_{\mathrm{i}}\right)$ dividido pelo número de palmeiras vivas no começo do ano. $\left(\mathrm{n}_{\mathrm{i}}\right)$.

$$
\sigma_{\mathrm{i}}=\mathrm{S}_{\mathrm{i}} / \mathrm{n}_{\mathrm{i}}
$$

A taxa de transição $\left(\gamma_{i}\right)$ de indivíduos de uma classe de tamanho para a próxima foi obtida considerando o número de indivíduos que passaram de uma classe para a próxima durante o ano. Para todas as classes de tamanho as taxas de transição foram calculadas como o número de novas palmeiras que deixaram a classe de tamanho i e apareceram anualmente na próxima classe de tamanho $\left(\mathbf{r}_{\mathrm{i}}\right)$, dividido pelo número de palmeiras que permaneceram vivas na classe de tamanho i no começo do ano e tinham sobrevivido no próximo ano $\left(\mathrm{S}_{\mathrm{i}}\right)$.

$$
\gamma_{i}=r_{i} / S_{i}
$$

O número de plântulas produzidas por palmeira reprodutiva por ano (taxa de fecundidade - F) foi expresso em termos da média do número de plântulas produzidas por adultos; como sugerido por Caswell (1989) para espécies cujas sementes germinam em menos que um ano.

Um modelo de matriz de transição estruturado por classes de tamanho (Lefkovich, 1965) foi aplicado para a análise do crescimento populacional do açaizeiro das áreas estudadas. Caswell (1989) fez uma revisão do modelo de matriz estruturado pelo tamanho (Lefkovich, 1965) e o apresentou através da equação (4):

$$
\mathrm{n}_{\mathrm{t}+1}=\mathrm{M} * \mathrm{n}_{\mathrm{t}}
$$

onde $\mathrm{n}_{\mathrm{t}+1}$ é a distribuição de classes de tamanho no tempo $\mathrm{t}+1 ; \mathrm{M}$ é a matriz quadrada, com linha e colunas, descrevendo as probabilidades de transição entre as classes de tamanho de um período a outro e $\mathrm{n}_{\mathrm{t}}$ é o vetor das classes de tamanho no intervalo de tempo $t$.

A matriz quadrada (M), representada na Figura 2, possui os valores de fecundidade (F) de adultos no canto superior direito, os valores de (P) na diagonal principal, que representam as probabilidades dos indivíduos permanecerem em uma dada classe e os valores de $(G)$ na subdiagonal que representam as probabilidades dos indivíduos de sobreviverem e passarem para a próxima classe de tamanho. 


\section{ACTA AMAZONICA}

\begin{tabular}{cccc}
\hline \hline $\mathrm{P}_{1,1}$ & 0 & 0 & $\mathrm{~F}_{4,1}$ \\
$\mathrm{G}_{1,2}$ & $\mathrm{P}_{2,2}$ & 0 & 0 \\
0 & $\mathrm{G}_{2,3}$ & $\mathrm{P}_{3,3}$ & 0 \\
0 & 0 & $\mathrm{G}_{3,4}$ & $\mathrm{P}_{4,4}$ \\
\hline \hline
\end{tabular}

Figura 2 - Matriz de transição com valores de Fecundidade (Fij), Probabilidades de permanência e sobrevivência na mesma classe de tamanho (Pij) e probabilidades de passar para a próxima classe de tamanho (Gij).

A multiplicação da matriz de transição pelo vetor coluna fornece o tamanho e a estrutura de classes de tamanho da população em um intervalo de tempo no futuro. Uma propriedade deste tipo de matriz de transição (M) é que quando é multiplicada várias vezes pela estrutura de classes inicial $\left(\mathrm{n}_{\mathrm{f}}\right)$, cada classe de tamanho tende a aumentar em uma taxa constante que é a raiz latente dominante da matriz $(\lambda)$ Caswell, (1989). Este número $\lambda$ é chamado de "taxa de crescimento populacional" e é uma medida do balanço entre sobrevivência e reprodução.

Daí, a equação (4) pode ser descrita da seguinte forma:

$$
\mathrm{n}_{\mathrm{t}+1}=\lambda * \mathrm{n}_{\mathrm{t}}
$$

onde: $\mathrm{n}_{\mathrm{t}+1}$ é a distribuição de classes de tamanho no tempo $\mathrm{t}+1$

\section{$\lambda$ é a taxa de estabilidade da população}

$n_{\mathrm{t}}$ é o vetor das classes de tamanho no intervalo de tempo $t$.

A população em equilíbrio cresce em uma taxa constante ( $\lambda$ ) sem alterar sua estrutura (Caswell, 1989). Um $\lambda$ maior que 1,0 indica que a população está aumentando em tamanho, um $\lambda$ menor que 1,0 que a população está diminuindo em tamanho. Um $\lambda$ igual a 1,0 indica que as taxas de nascimento $\mathrm{e}$ de morte são equilibradas de forma que a população permanece estável (Caswell, 1989; Pinard \& Putz,1992).

A aplicação do modelo matricial depende de sua sensibilidade para as alterações na estimativa dos parâmetros demográficos da população (taxas de sobrevivência, fecundidade e transição) (Silva Matos, 1995; Fisch, 1998) Assim, a análise de sensibilidade fornece a importância relativa de cada parâmetro para o $\lambda$ em cada classe de tamanho (Kroon et al. 1986).

A análise de sensibilidade é o produto dos autovetores direito (distribuição estádio-estável W) e esquerdo (valor estável-reprodutivo V) e é dada pela fórmula (6) Caswell (1989):

$$
\mathrm{S}_{\mathrm{ij}}=\mathrm{V}_{\mathrm{i}} \mathrm{W}_{\mathrm{j}}(\mathrm{V}, \mathrm{W})
$$

onde $S_{\mathrm{ij}}$ é a sensibilidade do $\lambda$ para mudanças nos elementos $a_{i j}$ da matriz; $V$ é a estrutura estádio-estável de classes de tamanho (vetor eigen esquerdo); W é valor estávelreprodutivo de cada classe (vetor eigen direito).

\section{Produção de frutos}

A análise da produção de frutos foi feita apenas nas florestas de baixio e de terra firme do Sítio São Pedro, Seringal Caquetá, Acre (Tabela 1).

Para a análise da produção anual de frutos por palmeira foram avaliados 20 indivíduos adultos amostrados aleatoriamente (10 na floresta de baixio e 10 na floresta terra firme), dos quais foram extraídos os seus cachos.

Para cada indivíduo adulto foram avaliados: (1) o número de cachos; (2) peso dos cachos (frutos + raquis), utilizando uma balança com capacidade de $20 \mathrm{~kg}$ e graduação $0,5 \mathrm{~kg}$; (3) peso dos frutos sem a raquis; (4) peso de frutos, com balança digital com precisão de $0,1 \mathrm{~g}$. O peso médio $(\mathrm{kg})$ de frutos foi calculado a partir da pesagem de 100 frutos. Como houve cachos que não foram pesados por seus frutos estarem verdes, para estes, o cálculo da produção foi feito considerando o peso médio dos cachos maduros que foram pesados.

Estas medidas foram realizadas em junho de 2000, época de baixa pluviosidade na região e que também a frutificação do açaizeiro está acabando no baixio e iniciando-se na terra firme (depoimento dos moradores locais).

\section{RESULTADOS E DISCUSSÃO}

\section{Estrutura populacional e densidade de Euterpe precatoria}

A variação das distribuições de tamanho nas populações amostradas de Euterpe precatoria é demonstrada nas Figuras 3 e 4 . Todas as áreas apresentaram maiores números de plântulas e jovens 1, em relação aos jovens 2 e adultos. Esta distribuição é encontrada em populações naturais que possuem alta regeneração in locus e que provavelmente têm suas densidades estáveis (Hall \& Bawa, 1993; Peters, 1996; Meyer, 1952, citado por Pinard \& Putz, 1992). Este tipo de distribuição populacional é comumente referido como "J invertido". Outras palmeiras neo-tropicais com esta estrutura são Euterpe edulis (Fisch, 1998; Silva Matos, 1995; Reis, 1995); Astrocaryum mexicanum (Van Valen, 1975; Sarukhan, 1980, citados por Fisch, 1998), Iriartea deltoidea (Pinard, 1993), Phytelephas seemanii (Bernal, 1998).

$O$ padrão encontrado no presente trabalho pode ser devido, entre outros fatores, à mortalidade causada por injúrias mecânicas pela queda de galhos, árvores e folhas (Piñeiro et al., 1984). Em classes de tamanho maiores estas injúrias dificilmente causam a morte, mas podem retardar o desenvolvimento como observado em outras palmeiras, como Pococcus barteri (Bullock, 1980) e Astrocaryum mexicanum (Sarukhán et al. 1984). Outras causas de mortalidade nas fases iniciais de desenvolvimento podem ser a herbivoria (Howe \& Smallwood 1982 citado por Zuidema \& Boot, 2000), e a competição por recursos como água, nutrientes e luz (Swaine, et al. 1987). Na área de 

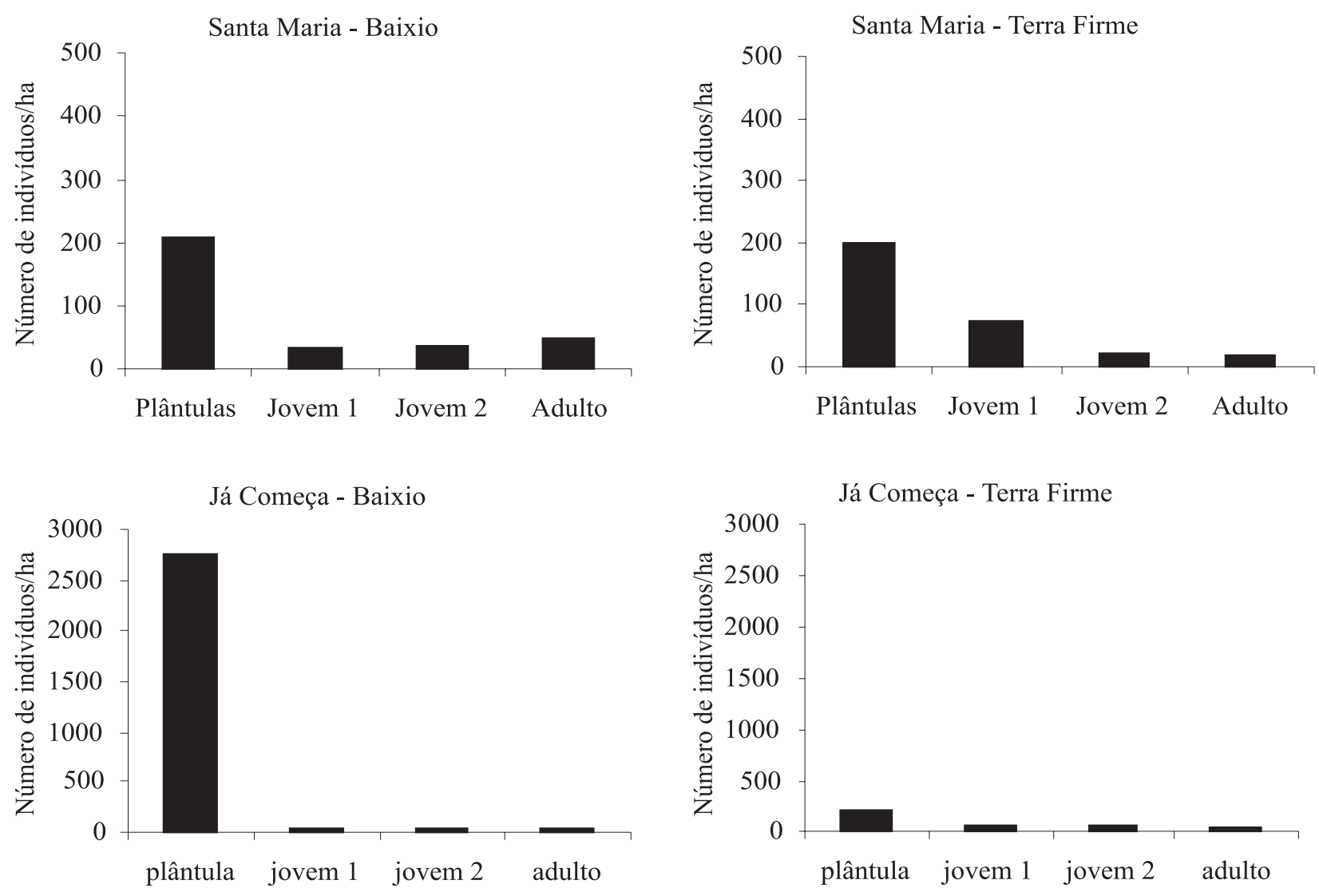

Figura 3 - Estrutura populacional de Euterpe precatoria amostrada nas Florestas de baixio (1 ha) e de terra firme (1 ha) dos sítios Santa Maria (Seringal Porongaba, Município de Brasiléia) e Já Começa (Seringal Dois Irmãos, Município de Xapuri), AC, Brasil.

estudo não foi observado a herbivoria como causa da mortalidade das plântulas (observação pessoal).

A ocorrência de Euterpe precatoria em florestas alagadas e não-alagadas, como observado no presente estudo, também foi observado por Kahn \& Henderson (1999) entre outros.

O número médio de adultos na floresta de baixio foi de $60 \pm 19$ indivíduos ha ${ }^{-1}$ e na floresta de Terra firme foi de $28 \pm 9$ (Tabela 2). Esta diferença entre baixio e terra firme foi estatisticamente significativa (teste Kruskal-Wallis; $\mathrm{p}<$ $0,01 ; n=6)$. A densidade de adultos do açaizeiro varia de 25 (Zuidema \& Boot, 2000) em floresta de terras baixas na Bolívia; e de 50 a 250 plantas ha ${ }^{-1}$ na Amazônia peruana (Kahn, 1988, citado por Castro \& Bovi, 1993).

Em uma floresta secundária com dossel acima de $30 \mathrm{~m}$ no Amazonas, município de Manaquiri, Castro (2000) encontrou 232 indivíduos férteis em um hectare. Este valor é praticamente o dobro do valor encontrado para a área mais densa no presente estudo (118 indivíduos ha-1), localizada no sítio Arraia (Tabela 2).

Na Bolívia, E. precatoria é encontrada também em florestas inundadas sazonalmente e de terra firme, além de áreas de savana (Moraes 1996, Pena-Claros \& Zuidema,
1999, citados por Zuidema \& Boot, 2000). A densidade encontrada nas florestas inundadas e ilhas de florestas em áreas de savana foi de 260 indivíduos ha ${ }^{-1}$ (Pena-Claros \& Zuidema, 1999, citado por Zuidema \& Boot, 2000), enquanto que em florestas de terra firme foi de 23 indivíduos $\mathrm{ha}^{-1}$. Estes valores são cerca de 4 vezes maiores do que o encontrado no presente estudo para baixio, porém similares para a terra firme. Maiores densidades do açaizeiro em florestas de baixio em relação a terra firme também foram observadas, por outros estudos, como por exemplo, por Peres (1994), próximo ao Rio Urucu no Amazonas.

Apesar do número médio de indivíduos por hectare ter sido maior na floresta de baixio que na terra firme, a variância do número de plântulas, jovem 1 , jovem 2 e adultos foi 103, 8, 1 e 6 vezes maior no primeiro tipo florestal comparando com o segundo, respectivamente. Estes valores sugerem que no baixio, os indivíduos estejam mais heterogeneamente distribuídos que na terra firme. Um exemplo desta variação em baixio é a discrepância dos valores encontrados no sítio Arraia com 118 indivíduos ha-1, que é o dobro da média de todos baixios (Tabela 2). Este valor discrepante pode estar relacionado tanto com a variação natural da distribuição dos indivíduos ao longo de 

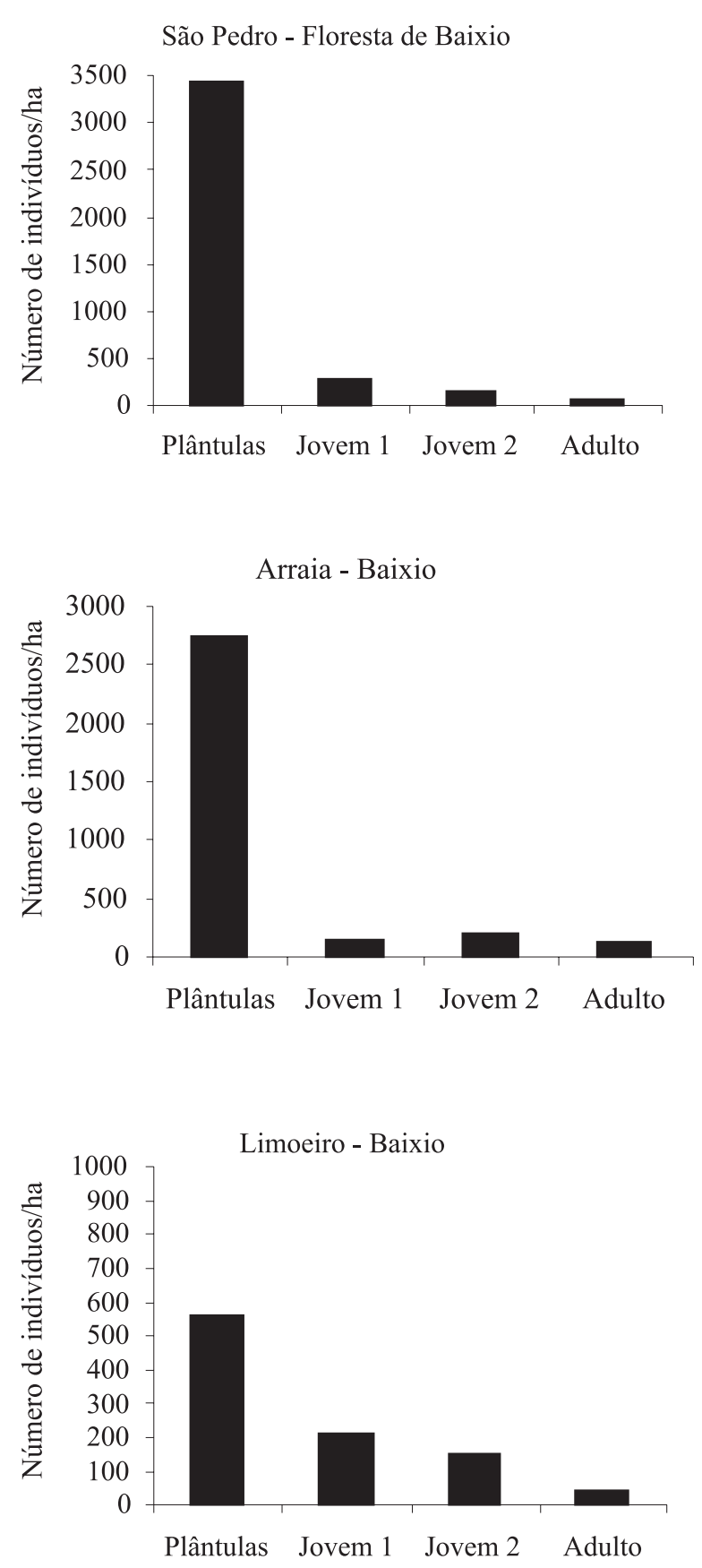

São Pedro- Floresta de Terra Firme
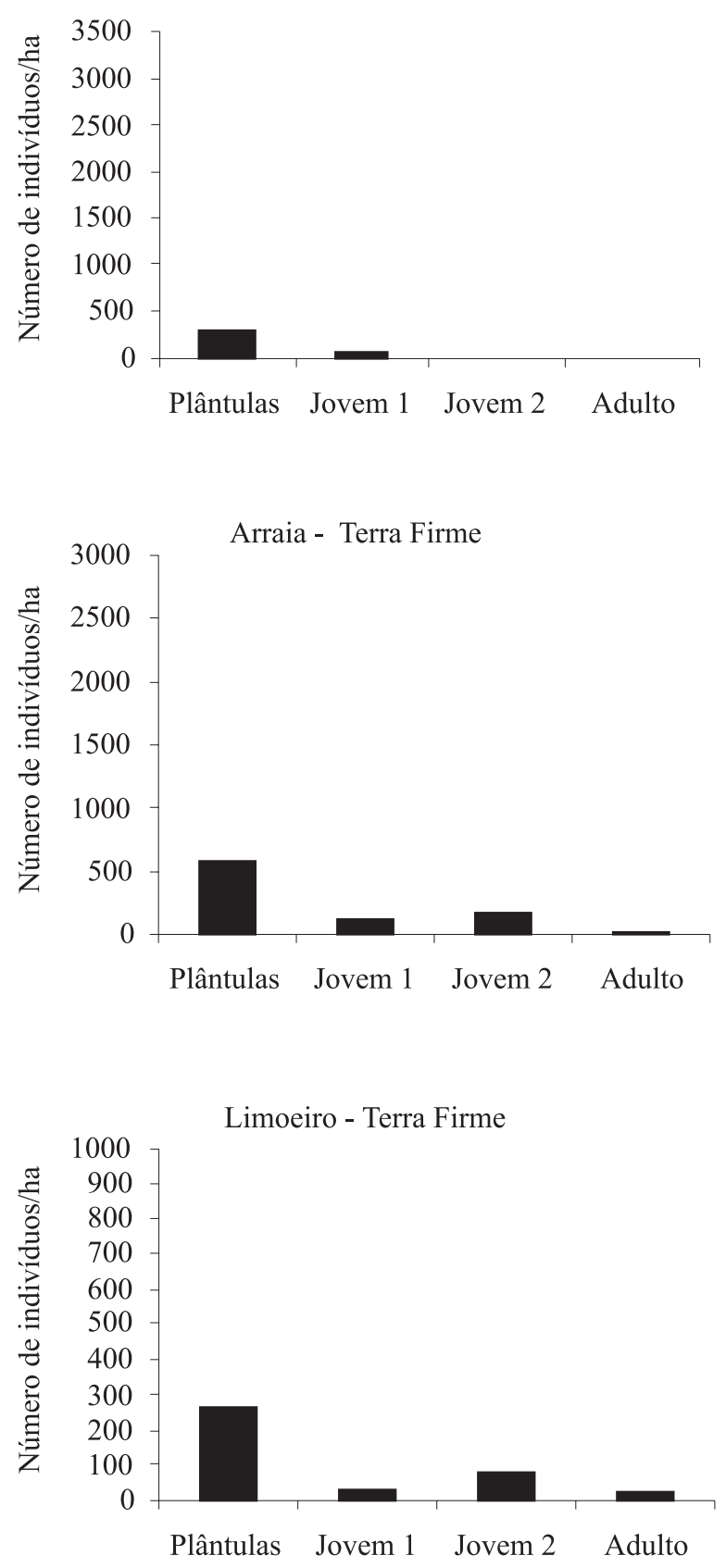

Figura 4 - Estrutura populacional de Euterpe precatoria nas Florestas de baixio (1 ha) e de terra firme (1 ha) dos sítios São Pedro, Arraia, Limoeiro e Morada Nova no Seringal Caquetá - Município de Porto Acre, AC, Brasil.

tipos florestais no Vale do Rio Acre, quanto com o fato de no passado, poder ter ocorrido um plantio ou adensamento da espécie pelos moradores locais deste sítio.

Observações de campo em todas as áreas de baixio e de terra firme evidenciaram que dentro do primeiro tipo de floresta, formam-se agrupamentos densos de indivíduos muito próximos uns dos outros, enquanto que na terra firme, os indivíduos se encontram mais esparsos. Isto também foi demonstrado pela distância média entre os indivíduos no baixio e na terra firme (Tabela 3). Independentemente da classe de tamanho e da área amostrada, a distância média entre os indivíduos foi menor 


\section{ACTA \\ AMAZONICA}

POTENCIAL ECOLÓGICO PARA O MANEJO DE FRUTOS DE AÇAIZEIRO

(Euterpe precatoria MART.) EM ÁREAS EXTRATIVISTAS NO ACRE, BRASIL na floresta de baixio, que na floresta de terra firme.

Euterpe precatoria ocorreu em $100 \%$ dos hectares amostrados no baixio e na terra firme. Boom (1986) trabalhando na Amazônia boliviana inventariou todas as árvores maiores que $10 \mathrm{~cm}$ de DAP em um transecto de um 1ha na floresta tropical de terra firme ao longo do Rio Ivon, e encontrou o Açaizeiro como uma das espécies mais freqüentes.

A regra na floresta tropical é a alta diversidade de espécies vegetais e a distribuição não igualitária de indivíduos entre estas espécies (Heywood, 1995). Por convenção, espécies raras são aquelas com menos de um indivíduo adulto por hectare, e espécies comuns aquelas acima dessa densidade (Kageyama \& Lepsch-Cunha, 2001).

Considerando esta definição operacional em um gradiente nas comunidades desde as espécies muito raras até as muito comuns, a espécie estudada pode ser considerada comum nas áreas de estudo em ambos os tipos de florestas. Algumas evidências deste fato foram (1) a pequena distância média entre os indivíduos, (2) a alta freqüência de indivíduos, (3) a curva populacional na forma de $\mathrm{J}$ invertido tanto nas florestas de baixio quanto nas de terra firme amostradas.

A curva de freqüência de tamanho, as altas densidades e freqüência encontradas para a palmeira nas áreas amostradas são características de espécies classificadas como tolerantes (Denslow, 1980) em relação as sua estratégia de regeneração, onde sua germinação, crescimento e alcance da maturidade reprodutiva ocorrem sob as condições da floresta madura e sob o dossel.

A tolerância de E. precatoria à sombra implica na formação de bancos de plântulas sob o dossel, proporcionando uma alta taxa de germinação, já que o banco de sementes é muito passageiro no solo, assim como o encontrado para Euterpe edulis que germina no período de 4 a 6 meses no banco (Reis, 1995; Fisch, 1998).

Com relação à variação entre baixio e terra firme, a competição interespecífica pode ser uma possível causa da (1) diferença de densidade da palmeira, (2) de uma maior heterogeneidade da distribuição dos indivíduos no primeiro tipo de floresta. É possível que uma menor competição com outras espécies devido ao alagamento seja uma causa responsável pelas maiores densidades de açaizeiros nestes locais. Desta forma, apesar de Euterpe precatoria crescer em florestas de terra firme, existem outras espécies que podem também crescer em áreas que não alagam em uma taxa muito mais rápida. Estas espécies, porém, podem ter problemas com habitats inundados (Peters, comunicação pessoal).

A alta densidade, freqüência e estrutura em forma de J invertido sugerem que Euterpe precatoria tem um alto potencial de manejo conforme proposto por Peters (1996). Um maior potencial de manejo apresentou-se na floresta de baixio comparado a terra firme.

\section{Dinâmica populacional}

A taxa e a probabilidade de sobrevivência do açaizeiro foram maiores para jovens 2 e adultos que para plântulas e jovens 1 , independente do sítio e tipo de floresta amostrados, assim como encontrado por Zuidema \& Boot (2000) para a espécie em florestas de terras baixas na Bolívia. O padrão de sobrevivência em relação ao tamanho da planta foi similar ao encontrado para outras espécies de palmeiras (Enright \& Watson, 1992 citado por Zuidema \& Boot, 2000).

Castro \& Bovi (1993) encontraram uma sobrevivência de plântulas de $E$. precatoria baixa, na fase de folha única até as plantas terem aproximadamente $50 \mathrm{~cm}$ de altura. Fatores 


\section{ACTA AMAZONICA}

como a disponibilidade de água, nutrientes e luz (Swaine, $e t$ al., 1987), herbivoria, danos físicos pela queda de árvores e/ ou galhos, comumente afetam a mortalidade da população de várias espécies de palmeiras (Zuidema \& Boot, 2000).

A sobrevivência e a transição da população foram maiores na terra firme do que no baixio dos dois sítios amostrados. Apesar disto, após um ano de recenseamento foi encontrado no sítio São Pedro um número de indivíduos cerca de 9 vezes maior, e no sítio Já Começa, 5 vezes maior no baixio em relação a terra firme. Além disso, a fecundidade durante o período de 1 ano foi aproximadamente 3,4 e 4,5 vezes maior no baixio que na terra firme nos sítios São Pedro e Já Começa respectivamente (Tabela 4 ).

No sítio São Pedro a menor taxa de transição de plântulas no baixio pode estar relacionada com uma maior mortalidade desta classe neste tipo de floresta quando comparado com a terra firme. Mesmo assim, a taxa de transição de $12 \%$ no baixio representou um maior número de indivíduos que passaram de plântulas para jovem 1 , que o número de plântulas encontrado no censo inicial da densidade na terra firme. A terra firme deste sítio apresentou taxa de transição zero para jovens 2 no período estudado. A transição zero pode ser devido ao período de tempo de apenas 1 ano de avaliação. O curto período não seria tempo suficiente para haver transição de uma classe de tamanho à outra. Outro motivo para a transição de jovens 2 ter sido zero pode ser o pequeno número de indivíduos amostrados neste tipo florestal (Tabela 4).

A taxa de sobrevivência dos adultos apresentou-se maior no baixio do que na terra firme.

Tabela 3 - Distância média entre os indivíduos de Euterpe precatoria na floresta de baixio e de terra firme dos sítios Arraia, Limoeiro, São Pedro e Já Começa, AC, Brasil.

\begin{tabular}{lcccc}
\hline \hline FLORESTA DE BAIXIO & \multicolumn{4}{c}{ DISTÂNCIA ENTRE OS INDIVÍDUOS } \\
\hline Sítios & Plântula & Jovem 1 & Jovem 2 & Adulto \\
\hline Arraia & 2,2 & 9,3 & 7,7 & 9,9 \\
Limoeiro & 4,8 & 7,7 & 9,0 & 16,3 \\
São Pedro & 1,9 & 6,6 & 9,5 & 16,0 \\
Já Começa & 2,1 & 16,3 & 17,8 & 16,8 \\
Média & 2,7 & 10,0 & 11,0 & 14,7 \\
Desvio padrão da média & 1,3 & 4,3 & 4,6 & 3,2 \\
\hline FLORESTA DE TERRA FIRME & DISTÂNCIA ENTRE OS INDIVÍDUOS \\
\hline Sítios & Plântula & Jovem 1 & Jovem 2 & Adulto \\
\hline Arraia & 4,7 & 9,9 & 8,8 & 20,3 \\
Limoeiro & 6,9 & 21,3 & 12,6 & 21,7 \\
São Pedro & 6,4 & 16,0 & 56,4 & 34,0 \\
\hline Já Começa & 7,7 & 14,6 & 15,1 & 17,0 \\
Média & 6,4 & 15,4 & 23,2 & 23,2 \\
Desvio padrão da média & 1,3 & 4,7 & 22,3 & 7,4 \\
\hline \hline
\end{tabular}

No sítio Já Começa apenas o número de plântulas foi 10 vezes maior no baixio que na terra firme. O número de adultos foi aproximadamente o mesmo (Tabela 4).

A taxa de transição total das classes menores para a classe de tamanho adulto foi $1 \%$ maior na terra firme que no baixio. Isto foi refletido na densidade semelhante de adultos (baixio com 46 e terra firme com 45 indivíduos) entre os dois tipos florestais neste sítio. Provavelmente o maior número de plântulas no baixio em relação a terra firme para o sítio Já Começa esteja ligado à fecundidade aproximadamente 4,5 vezes maior no primeiro tipo florestal.

A estimativa da taxa de aumento populacional $(\lambda)$ para o açaizeiro na floresta de baixio do São Pedro, foi de 1,021 e isto pode ser devido à estabilidade crescente $(>1)$ da população na floresta de baixio. Na floresta de terra firme do mesmo sítio o valor encontrado foi de 1,000, que representa uma população estável na densidade. Estes resultados indicam uma dinâmica populacional distinta nas florestas de baixio e de terra firme do São Pedro.

A estimativa da taxa de aumento populacional $(\lambda)$ para o açaizeiro na floresta de baixio do sítio Já Começa foi de 0,977 e isto indica estabilidade decrescente $(<1)$ da população. Na floresta de terra firme do mesmo sítio o valor encontrado foi de 0,953 para a taxa de crescimento populacional, que representa uma população também decrescente na densidade.

Os valores da taxa de crescimento populacional são maiores na floresta de baixio que na de terra firme em ambos sítios amostrados. Este dado sugere haver um maior potencial de colheita de frutos no baixio. Os valores encontrados no Já Começa apresentaram-se menores que aqueles encontrados no São Pedro. Isto pode ser devido a diferenças naturais na distribuição da espécie no Vale do Rio Acre ocasionadas por diferenças de dispersão e predação de sementes, ou ainda devido a diferenças climáticas de precipitação e temperatura ocorridas entre os diferentes anos amostrados.

Zuidema \& Boot, (2000), estudando Euterpe precatoria na Bolívia encontraram um $\lambda$ de 0,977 . Este valor decrescente parece estar relacionado com a intensa colheita de indivíduos adultos para a extração de palmito na área, já que a classe dos indivíduos reprodutivos contribui muito para o valor de $\lambda$. No Já Começa não foram observados indivíduos adultos cortados e mesmo assim o seu $\lambda$ foi de 0,960 . Portanto, este valor pode não estar diretamente relacionado ao impacto de extração.

A taxa de crescimento $(\lambda)$ de uma 


\section{ACTA AMAZONICA}

POTENCIAL ECOLÓGICO PARA O MANEJO DE FRUTOS DE AÇAIZEIRO

(Euterpe precatoria MART.) EM ÁREAS EXTRATIVISTAS NO ACRE, BRASIL população de Euterpe precatoria na floresta de terras baixas da Bolívia durante um ano típico em relação à precipitação foi 0,977 , e durante o ano seco um pouco mais baixa, 0,960. A diferença entre estes valores pode ser explicada pelas taxas de crescimento mais baixas em jovens 2 e adultos, durante o ano seco, e também pelo recrutamento e sobrevivência muito reduzidos que segue o ano seco (Zuidema \& Boot, 2000).

Para populações de outras espécies de palmeira foram encontrados valores de $\lambda$ como 1,16 para Euterpe edulis (Fisch, 1998), 1,05 para Phytelephas seemanii (Bernal, 1998), 0, 98 e 1,01 para Iriartea deltoidea (Pinard 1993), 1,01 para Podoccocus bartieri (Bullock, 1980).

$\mathrm{Na}$ floresta de baixio do São Pedro a sensibilidade foi maior com $(G)$ seguida de $(P)$ e de $(F)$ para as plântulas, jovens 1 e 2 . Para os adultos a maior sensibilidade para o valor de $\lambda$ foi a de (P) e a menor foi atribuída ao parâmetro G (Tabela 5). Na terra firme do mesmo sítio as plântulas e jovens 1 contribuem mais com o $\mathrm{G}$ enquanto que os jovens 2 e os adultos contribuem mais com P. Para os jovens 2 isto provavelmente aconteceu porque a taxa de transição foi zero para esta classe no período estudado (Tabela 4). A taxa de transição zero atribuída para os jovens 2 na terra firme do São Pedro provavelmente está relacionada com o baixo número de indivíduos amostrados desta classe na área, ou ainda pode ser devido ao curto período de tempo estudado ( 1 ano).

$\mathrm{O}$ valor reprodutivo aumentou de plântulas para adultos nos dois sítios amostrados, e independente do tipo de floresta, apresentando certamente valores máximos em adultos.

A maior contribuição para o valor de $\lambda$ na floresta de baixio do sítio São Pedro foi do parâmetro demográfico $\mathrm{G} \mathrm{e}$ não do P. Isto pode estar diretamente relacionado com as condições ambientais do baixio analisado que possui maior penetração de luz no subosque e maior disponibilidade de água em relação à terra firme (observação pessoal). As menores luminosidade e umidade da terra firme fazem com que (P) de um ano a outro contribua mais para o valor de $\lambda$ que $(\mathrm{G})$. Além disso, pela maior diversidade encontrada em

Tabela 4 - Número de palmeiras por hectare $\left(\right.$ palmeiras ha-1 ${ }^{-1}$ ), taxas de sobrevivência $\left(s_{\mathrm{i}}\right)$, taxas de transição $\left(\mathrm{y}_{\mathrm{i}}\right)$ para a próxima classe de tamanho e número de novos recrutas por adulto (recrutas palmeira ${ }^{-1}$ ) de Euterpe precatoria na floresta de baixio e terra firme dos sítios São Pedro e Já Começa no AC, Brasil. Indivíduos divididos em 4 classes de tamanho.

\begin{tabular}{|c|c|c|c|c|}
\hline \multicolumn{5}{|c|}{ FLORESTA DE BAIXIO - SÍTIO SÃO PEDRO } \\
\hline Classe de tamanho & Plântula & Jovem 1 & Jovem 2 & Adulto \\
\hline Palmeiras ha ${ }^{-1}$ & 3432 & 290 & 142 & 50 \\
\hline Taxa de sobrevivência $\left(\sigma_{i}\right)$ & $0,43(43 \%)$ & $0,78(78 \%)$ & $0,97(97 \%)$ & $0,96(96 \%)$ \\
\hline Taxa de transição $\left(\mathrm{y}_{\mathrm{i}}\right)$ & $0,12(12 \%)$ & $0,09(9 \%)$ & $0,03(3 \%)$ & 0 \\
\hline Recrutas palmeira ${ }^{-1}$ & 0 & 0 & 0 & 9,34 \\
\hline \multicolumn{5}{|c|}{ FLORESTA DE TERRA FIRME - SÍTIO SÃO PEDRO } \\
\hline Classe de tamanho & Plântula & Jovem 1 & Jovem 2 & Adulto \\
\hline Palmeiras ha ${ }^{-1}$ & 308 & 50 & 4 & 11 \\
\hline Taxa de sobrevivência $\left(\sigma_{i}\right)$ & $0,49(49 \%)$ & $0,63(63 \%)$ & $1(100 \%)$ & $0,91(91 \%)$ \\
\hline Taxa de transição $\left(\mathrm{y}_{\mathrm{i}}\right)$ & $0,21(21 \%)$ & $0,07(7 \%)$ & 0 & 0 \\
\hline Recrutas palmeira $^{-1}$ & 0 & 0 & 0 & 2,72 \\
\hline \multicolumn{5}{|c|}{ FLORESTA DE BAIXIO - SÍTIO JÁ COMEÇA } \\
\hline Classe de tamanho & Plântula & Jovem 1 & Jovem 2 & Adulto \\
\hline Palmeiras ha ${ }^{-1}$ & 2756 & 58 & 40 & 46 \\
\hline Taxa de sobrevivência $\left(\sigma_{i}\right)$ & $0,41(41 \%)$ & $0,75(75 \%)$ & $0,85(85 \%)$ & $0,98(98 \%)$ \\
\hline Taxa de transição $\left(\mathrm{y}_{\mathrm{i}}\right)$ & 0 & $0,06(6 \%)$ & $0,12(12 \%)$ & 0 \\
\hline Recrutas palmeira $^{-1}$ & 0 & 0 & 0 & 4,52 \\
\hline \multicolumn{5}{|c|}{ FLORESTA DE TERRA FIRME - SÍTIO JÁ COMEÇA } \\
\hline Classe de tamanho & Plântula & Jovem 1 & Jovem 2 & Adulto \\
\hline Palmeiras ha ${ }^{-1}$ & 216 & 60 & 60 & 45 \\
\hline Taxa de sobrevivência $\left(\sigma_{i}\right)$ & $0,57(57 \%)$ & $0,83(83 \%)$ & $0,71(71 \%)$ & $0,95(95 \%)$ \\
\hline Taxa de transição $\left(\mathrm{y}_{\mathrm{i}}\right)$ & $0,01(1 \%)$ & 0 & $0,2(20 \%)$ & 0 \\
\hline Recrutas palmeira $^{-1}$ & 0 & 0 & 0 & 1 \\
\hline
\end{tabular}




\section{ACTA AMAZONICA}

florestas de terra firme em relação às florestas de inundação (Kanh \& De Granville, 1992) é provável que exista uma maior competição interespecífica com o açaizeiro por luz, nutrientes entre outros na terra firme.

$\mathrm{Na}$ floresta de baixio do Já começa (G) contribuiu com maior sensibilidade para a taxa de crescimento populacional, seguida por (P) e (F) para os jovens 1 e 2. Para as plântulas o parâmetro (P) contribuiu mais porque a taxa de transição no período estudado foi zero. Para os adultos a maior sensibilidade para o valor de $\lambda$ foi a de (P) e a menor foi atribuída ao parâmetro $\mathrm{G}$ (Tabela 5 ). Na terra firme do mesmo sítio as plântulas e jovens 2 contribuem mais com o $\mathrm{G}$ enquanto que os jovens 1 e os adultos contribuem mais com P. Para os jovens 1 isto provavelmente aconteceu porque a taxa de transição foi zero.

Considerando a população total a probabilidade de sobrevivência foi a taxa vital mais importante para determinar o $\lambda$, seguido pelo crescimento e reprodução, assim como o encontrado por Zuidema \& Boot (2000) estudando Euterpe precatoria na Bolívia.

Piñero et. al. (1984) consideraram que para espécies arbóreas a importância relativa (sensibilidade) dos parâmetros para o $\lambda$ da matriz segue a seguinte ordem: $(F)<(P)<(G)$. Porém, discutem que são as condições ambientais onde a população está crescendo que determinam os padrões de sensibilidade encontrados.

Os valores de $\lambda$ calculados neste estudo sugerem que os frutos do açaizeiro podem ser coletados sustentavelmente na floresta de baixio do sítio São Pedro, porque o valor de $\lambda$ foi crescente. Na Floresta de terra firme deste sítio o crescimento populacional demonstrou-se constante $(\lambda=1)$, o que sugere menor potencial de colheita.
Os valores de $\lambda$ calculados nas florestas de baixio e terra firme do sítio Já Começa sugerem que neste local a população está decrescendo e, portanto podem-se ter problemas futuros para a manutenção da densidade da população caso seus frutos forem coletados.

Considerando a variação de ambos os sítios, e também devido ao pequeno período de tempo ( 1 ano) estudado, estes valores devem ser confirmados através de novos recenseamentos para verificar se este padrão permanece ao longo dos anos. Zuidema \& Boot (2000) estudando a dinâmica de Euterpe precatoria na Bolívia encontraram uma variação do valor de $\lambda$ de ano para ano de 0,017 .

Deve-se considerar também que o modelo matricial aqui utilizado para o estudo da dinâmica populacional possui algumas limitações, pois estes modelos assumem que a dinâmica populacional não muda no tempo, o que pode ser pouco realista, devido à variação temporal nas condições ambientais. Além disto, estes modelos assumem que as taxas demográficas dos indivíduos são descritas adequadamente pelo seu valor médio (Zuidema \& Boot, 2000). Outros fatores que devem ser considerados são: (1) que a coleta de dados no presente estudo foi realizada no período de apenas 1 ano e (2) que a estrutura de estádio estável e o valor estável reprodutivo utilizados na análise de sensibilidade são válidos somente para um conjunto de valores de fecundidade, transição e sobrevivência para um intervalo de tempo específico (Viana, comunicação pessoal).

\section{Produção de frutos}

Os moradores do Seringal Dois Irmãos, sítio Já Começa e do Seringal Caquetá, sítio São Pedro informam que Euterpe

Tabela 5 - Sensibilidade da taxa de crescimento populacional (l) em relação às mudanças nas probabilidades de sobreviver e permanecer na mesma classe de plântulas $(\mathrm{P} 1,1)$, jovem $1(\mathrm{P} 2,2)$, jovem $2(\mathrm{P} 3,3)$ e adulto $(\mathrm{P} 4,4)$; sobreviver e passar para a classe de tamanho seguinte de plântulas $(\mathrm{G} 1,2)$, jovem $1(\mathrm{G} 2,3)$ e jovem $2(\mathrm{G} 3,4)$ e da fecundidade $(\mathrm{F} 4,1)$ encontradas para $E$. precatoria na Floresta de baixio e de terra firme e uma média dos dois tipos florestais no Sítio São Pedro, Seringal Caquetá, AC, Brasil.

\begin{tabular}{lcccccc}
\hline \hline & \multicolumn{6}{c}{ Sensibilidade } \\
\cline { 2 - 7 } & \multicolumn{2}{c}{ Seringal Caquetá, Sítio São Pedro } & \multicolumn{2}{c}{ Seringal Dois } & Irmãos, Sítio Já Começa \\
\cline { 2 - 7 } & baixio & terra firme & Média & baixio & terra firme & Média \\
\hline $\mathrm{P} 1,1$ & 1,5 & $6,1 \mathrm{E}-27$ & 1,5 & $4,5 \mathrm{E}-34$ & $5,1 \mathrm{E}-33$ & 0,3 \\
$\mathrm{G} 1,2$ & 18,5 & $3,6 \mathrm{E}-26$ & 17,5 & 0 & $2,6 \mathrm{E}-32$ & 21,6 \\
$\mathrm{P} 2,2$ & 3,1 & $9 \mathrm{E}-27$ & 3,0 & $6 \mathrm{E}-23$ & $1,2 \mathrm{E}-32$ & 0,9 \\
$\mathrm{G} 2,3$ & 14,1 & $9 \mathrm{E}-26$ & 14,3 & $3,9 \mathrm{E}-22$ & 0 & 13,8 \\
$\mathrm{P} 3,3$ & 12,5 & 100 & 13,4 & $6,9 \mathrm{E}-22$ & $4,2 \mathrm{E}-34$ & 0,5 \\
$\mathrm{G} 3,4$ & 34,4 & 0 & 34,9 & $1,6 \mathrm{E}-21$ & $1,1 \mathrm{E}-33$ & 1,2 \\
$\mathrm{P} 4,4$ & 15,9 & $4,2 \mathrm{E}-32$ & 15,5 & 100 & 100 & 61,7 \\
$\mathrm{~F} 4,1$ & 0,1 & $1,4 \mathrm{E}-33$ & 0,1 & $5,7 \mathrm{E}-35$ & $2,2 \mathrm{E}-33$ & 0,02 \\
\hline \hline
\end{tabular}

P1,1 = Probabilidade de plântulas sobreviverem e permanecerem na mesma classe de tamanho; P2,2 = Probabilidade de jovens 1 sobreviverem e permanecerem na mesma classe de tamanho; P3,3 = Probabilidade de jovens 2 sobreviverem e permanecerem na mesma classe de tamanho; $\mathrm{P} 4,4=$ Probabilidade de adultos

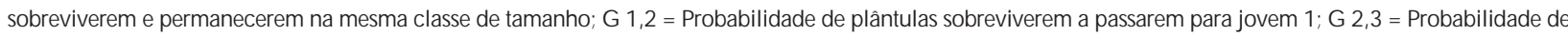
jovens 1 sobreviverem e passarem para jovens 2; G 3,4 = Probabilidade de jovens 2 sobreviverem e passarem para adultos. 0 período considerado é de 1 ano. 


\section{ACTA \\ AMAZONICA}

POTENCIAL ECOLÓGICO PARA O MANEJO DE FRUTOS DE AÇAIZEIRO

(Euterpe precatoria MART.) EM ÁREAS EXTRATIVISTAS NO ACRE, BRASIL precatoria frutifica anualmente, primeiro na floresta de baixio e depois na floresta de terra firme das suas áreas. A frutificação no sítio Já Começa foi de abril a setembro nos anos de 1997 a 1998. No sítio São Pedro, a frutificação foi de março a setembro em 1999 e de abril a setembro em 2000. A informação da frutificação anual corrobora com o encontrado por Rigamonte (comunicação pessoal) estudando a fenologia da frutificação do açaizeiro em uma floresta secundária em Rio Branco, Acre, pelo período de três anos.

Peres (1994) observando a fenologia da frutificação da mesma palmeira em florestas sazonalmente inundadas no Amazonas, encontrou que a espécie possui grande parte de seus frutos maduros entre os meses de fevereiro e julho.

A Tabela 6 mostra a estatística descritiva da produção de frutos do açaizeiro nas florestas de baixio e de terra firme do Seringal Caquetá, Município de Porto Acre (Tabela 1). As palmeiras apresentaram de um a três cachos por adulto independente do tipo de floresta. Wallace (1999), trabalhando em áreas da Reserva Extrativista Chico Mendes encontrou que E. precatoria produziu de 1 a 4 inflorescências, enquanto Castro (2000) encontrou que a palmeira produz de 3 a 4 cachos, mas raramente há mais que dois maduros ao mesmo tempo. No Seringal Caquetá foi encontrado que $12 \%$ dos indivíduos $(n=20)$ produziram três cachos que estavam maduros ao mesmo tempo. Em uma população no Peru as palmeiras produziram de duas a seis inflorescências por ano.

Em junho de 2000 obteve-se a média de produção de cachos de 1,8 na floresta de terra firme e 2,4 cachos no baixio e o peso médio total de frutos por palmeira na floresta de baixio foi de $7,5 \pm 4,2 \mathrm{~kg}$ e na floresta de terra firme foi de $6,2 \pm \pm 2,4 \mathrm{~kg}$ (Tabela 6). Estas diferenças não foram estatisticamente significativas (teste Kruskal-Wallis; $\mathrm{p}<0,05 ; \mathrm{n}=10$ ).

$\mathrm{O}$ peso total de frutos por cacho variou de 1 a $7,5 \mathrm{Kg}$. Assim, tanto o peso total de frutos de um cacho como o número de frutos estimados por cacho foram extremamente variáveis. Estas variações podem estar relacionadas com a variabilidade interanual, local do indivíduo, variação genética, ou ainda com a perda de frutos, provocada pela queda abaixo da planta mãe na hora da colheita e perdas causadas pelo vento e tempestades (Castro, 2000). A variação pode ser também devido a diferença de polinização entre inflorescências ou diferenças do número de frutos já comidos e/ou dispersados anteriormente à extração e medida.

$\mathrm{O}$ peso médio dos frutos foi de $1,14 \mathrm{~g}$. Este valor foi superior ao encontrado por Castro (2000), que encontrou $1 \mathrm{~g}$ por fruto no Amazonas.

Sabe-se que o rendimento vegetativo e reprodutivo muda de acordo com a situação ambiental. Quando ocorre a abertura de uma clareira, as espécies tolerantes entram em um período de intenso crescimento apical e elevada atividade reprodutiva que diminui com o fechamento da clareira. Em Astrocaryum mexicanum, a quantidade de frutos produzidos por indivíduo foi de 30,1 $\pm 2,8$ no subosque e 60,2 \pm 12,7 em clareiras (Piñero, et al. 1984). A freqüência da reprodução de um indivíduo entre os anos também variou para esta espécie em situações de maior e menor incidência luminosa.

Além disso, Phillips (1992) mostrou que apesar da baixa diversidade geral de espécies, as florestas de inundação produziam mais frutos do que as florestas de terra firme. Considerando-se que no presente estudo não foi encontrada maior produção de frutos por palmeira no baixio, mas que, no entanto a fecundidade e número de plântulas foi maior nesta tipologia, supõe-se um maior potencial produtivo pela diferença encontrada na densidade de adultos.

Para se saber se de fato não existe uma diferença de produção de frutos entre os dois tipos florestais estudados aqui, torna-se necessário que se faça medidas desta variável nos mesmos indivíduos ao longo de vários anos.

\section{CONCLUSÃO}

A espécie apresentou uma estrutura populacional com uma maior proporção de plântulas em relação a adultos.

A densidade de Euterpe precatoria apresentou-se alta e heterogênea nas florestas de baixio e de terra firme estudadas. Esta heterogeneidade demonstrou-se maior no primeiro tipo

Tabela 6 - Estatística descritiva da produção de frutos de Euterpe precatoria na floresta de baixio $(\mathrm{n}=10)$ e de terra Firme $(\mathrm{n}=10)$ do sítio São Pedro, AC, Brasil.

\begin{tabular}{|c|c|c|c|c|c|c|}
\hline & & $\begin{array}{l}\text { Número } \\
\text { de cachos }\end{array}$ & $\begin{array}{c}\text { Frutos/ } \\
\text { cacho (kg) }\end{array}$ & $\begin{array}{c}\text { Frutos/ } \\
\text { palmeira (kg) }\end{array}$ & $\begin{array}{c}\text { Número de } \\
\text { frutos/palmeira }\end{array}$ & $\begin{array}{c}\text { Número de } \\
\text { frutos/cacho }\end{array}$ \\
\hline \multirow[t]{4}{*}{ baixio } & Média & 2,4 & 3 & 7,5 & 6581 & 2673 \\
\hline & Desvio padrão & 0,7 & 1,5 & 4,2 & 3696 & 1243 \\
\hline & Máximo & 3 & 6 & 15 & 13272 & 4424 \\
\hline & Mínimo & 1 & 1 & 1,5 & 1316 & 877 \\
\hline \multirow{4}{*}{$\begin{array}{l}\text { terra } \\
\text { firme }\end{array}$} & Média & 1,8 & 3,6 & 6,2 & 5477 & 3221 \\
\hline & Desvio padrão & 0,6 & 1,7 & 2,4 & 2086 & 1409 \\
\hline & Máximo & 3 & 7,5 & 9 & 7895 & 6579 \\
\hline & Mínimo & 1 & 1 & 3 & 2632 & 1316 \\
\hline
\end{tabular}




\section{ACTA \\ AMAZONICA}

florestal do que no segundo, apesar da densidade dos indivíduos reprodutivos ter sido maior no baixio que na terra firme.

As palmeiras apresentaram-se mais próximas nas florestas que inundam periodicamente do que na terra firme. A freqüência de Euterpe precatoria foi de $100 \%$ em ambos tipos florestais.

A espécie apresentou uma taxa de crescimento populacional variável entre os sítios e tipos florestais. Estes valores podem estar relacionados com a heterogeneidade da estabilidade populacional em diferentes áreas, e também, podem sugerir que o potencial de manejo é maior no baixio do que na terra firme.

As florestas de baixio de ambos os sítios amostrados não apresentaram um padrão de sensibilidade dos parâmetros demográficos para a taxa de crescimento populacional, enquanto que na terra firme para ambos os sítios, a probabilidade de sobrevivência contribui significativamente para o valor de $\lambda$.

O parâmetro demográfico que mais contribuiu para o valor de $\lambda$ foi a sobrevivência dos adultos e o crescimento das plântulas e jovens 1 , independente do sítio e tipo de floresta. $\mathrm{Na}$ floresta de baixio do sítio São Pedro o componente que mais contribuiu para a taxa de crescimento populacional foi a probabilidade de jovens 2 passarem para a classe dos adultos.

Não houve diferença do peso total médio de frutos por palmeira no baixio e na terra firme no ano e época medidos. A produção estimada de frutos na floresta de baixio e de terra firme foi alta, porém, como a variação do peso de frutos por palmeira é muito grande, a avaliação da produção deve ser feita em indivíduos marcados ao longo de vários anos e em épocas distintas ao longo do ano, para que se tenha estimativa mais representativa da produção de frutos por palmeira.

Este estudo sugere que de modo geral Euterpe precatoria possui características ecológicas favoráveis para seu manejo sustentável, tais como alta densidade e freqüência, regeneração abundante e grande produção de frutos. Um maior potencial de manejo apresentou-se na floresta de baixio, quando comparado à terra firme, devido principalmente à densidade e estabilidade populacional.

\section{AGRADECIMENTOS}

Ao Professor Virgílio M. Viana do Laboratório de Silvicultura Tropical (LASTROP) da ESALQ, pela orientação; ao CNPq e ao Fundo Mundial para a Natureza (WWF) pela bolsa de estudo e apoio financeiro respectivamente; ao Parque Zoobotânico da Universidade Federal do Acre pela infra-estrutura; ao Cleber Ibraim Salimon pela ajuda na revisão do texto final. A todos os seringueiros que contribuíram para este trabalho.

\section{BIBLIOGRAFIA CITADA}

Bernal, R. 1998. Demography of vegetable ivory palm Phytelephas seemannii in Colombia and the impact of seed harvesting. Journal of Applied Ecology, 35: 64-74.

Boom, B. M. 1986. A forest inventory in Amazonian Bolivia. Biotropica, 18(4): 287-294.
Bullock, S. H. 1980. Demography of and undergrow the palm in litoral Cameron. Biotropica, 12 (4): 247-255.

Castro, A.; Bovi, M. L. A. 1993. Assaí. In: Clay, J. W.; Clement, C. R. (Eds.). Selected species and strategies to enhance income generation from Amazonian forests. FAO Forestry Paper. Rome. p.58-67.

Castro, A. 2000. O extrativismo do Açaí na Amazônia central. In: Emperaire, L.(Ed.). A floresta em jogo - o extrativismo na Amazônia Central. Editora UNESP. São Paulo. p.129-138.

Caswell, H. 1989. Matrix populations models. Sinauer, Sunderland. 328p.

Cottam, G.; Curtis, J.T. 1956. The use of distance measures in phytosociological sampling. Ecology, 37:451-460.

Denslow, J. L. 1980. Gap partitioning among tropical rain-forest trees. Biotropica, 12: 47-55.

Fearnside, P. M. 1992. Reservas Extrativistas: uma estratégia de uso sustentável. Ciência Hoje, 14(81): 15-17.

Fisch, S. T. V. 1998. Dinâmica de Euterpe edulis Mart. na floresta Ombrófila Densa Atlântica em Pindamonhangaba-SP. Tese de doutorado. Universidade de São Paulo, São Paulo, 126p.

Governo do Acre. 2000. Zoneamento ecológico-econômico do Acre (Zee). Ministério do Meio Ambiente e Programa Piloto para Proteção das Florestas Tropicais do Brasil.

Hall, P.; Bawa, K. 1993. Methods to assess the impact of extraction of non-timber tropical forest products on plant populations. Economic Botany 47(3): 234-247.

Henderson, A. 1995. The palms of the Amazon. Oxford, University Press, New York, 362p.

Heywood, V.H. 1995. Global Biodiversity Assessment. Cambridge University Press, New York. 1140p.

Hulbeit, S. H. 1984. Pseudoreplication and the design of ecological field's experiments Ecological Monographs, 54(2): 187- 211

Instituto Nacional de Colonização e Reforma Agrária (INCRA). 1997. Ante- projeto de viabilidade técnica do projeto de Assentamento Caquetá. Rio Branco - AC. Processo número 54260000183/9782. Divisão de Assentamento. SR 14/Z. Agosto.

Instituto Brasileiro de Geografia e Estatística (IBGE). 1993. Mapa da vegetação do Brasil. Secretaria de Planejamento, Orçamento e Coordenação da Presidência da República. Brasília, DF.

Kageyama, P.Y.; Lepsch-Cunha, N. M. 2001. Singularidade da biodiversidade nos trópicos. In: Garay I.; Dias B. (Eds.). Conservação da Biodiversidade em ecossistemas tropicais: Avanços conceituais e revisão de novas metodologias de avaliação e monitoramento. Editora Vozes, São Paulo. 432p.

Kahn, F.; De Granville, J. J. 1992. Palms in forest ecosystems of Amazonia. Springer, Berlim. 226p.

Kahn, F. 1993. Amazonian palms: food resources for the management of forest ecosystems. In: Hladik, C. M; Hladik, A.; Linares, O.F; Pagezy, H.; Semple, A.; Hadley, M. (Eds.) Tropical forests, people and food: biocultural interactions and applications to development. Parthenon Publishing Group Carnforth UK. p.153-162. 


\section{ACTA AMAZONICA}

POTENCIAL ECOLÓGICO PARA O MANEJO DE FRUTOS DE AÇAIZEIRO

(Euterpe precatoria MART.) EM ÁREAS EXTRATIVISTAS NO ACRE, BRASIL
Kahn F.; Henderson A. 1999. An Overview of the Palm of the Várzea in the Amazon Region. In: Padoch, C.; Ayres, J. M.; PinedoVasquez, M.; Henderson, H.(Eds.). Várzea diversity, development, and conservation of Amazonia's whitewater floodplains. The New York Botanical Garden Press. New York. p.187-193.

Kroon, H.; Plaisier, A.; Groenendael, J. V.; Caswell, H. 1986. Elasticity: The Relative Contribution of Demographic Parameters to Population Growth Rate. Ecology, 67(5): 1427-1431.

Küchmeister, H.; Gottsberger, I. S.; Gottsberger, G. 1997. Flowering, pollination, nectar standing crop, and nectaries of Euterpe precatoria (Arecaceae) an Amazonian rain forest palm. Pl. Syst. Evol., 206: 71-97

Lamotte, S. 1990. Fluvial dynamics and Sucession in the lower Ucayali basin, Peruvian Amazonia. For. Ecol. Manage, 33/34: $141-156$.

Lefkovitch, L. P. 1965. The study population growth in organisms grouped by stages. Biometrics, 21: 1-18.

Matteucci, S. D.; Colma, A. 1982. Metodologia para El Estudio de La Vegetacion. Secretaria General de la Organizacion de los Estados americanos; Programa Regional de Desarrollo Cientifico y Tecnológico, Washington, D. C. 168p.

Neumann, R.P.; Hirsch, E. 2000. Commercialization of Non Timber Forest Products: Review and Analysis of Research. CIFOR; FAO. Bogor, Indonésia.176P.

Peres, C. A . 1994. Composition, Density, and Fruiting Phenology of Arborescent Palms in an Amazonian Terra firme Forest. Biotropica, 26(3): 285-294.

Peters, C. M. 1996. The Ecology e Management of Non-Timber Forest Resources. The World Bank Washington, D.C. Paper number 322. $157 \mathrm{p}$.

Phillips, O. 1992. The potential for harvesting fruits in tropical rainforest - New data from Peru. Biodiversity and Conservation, 2: 18 -38.

Pinard, M. A. ; F. E. Putz. 1992. Population matrix models and palm resource management. Bulletin de institut français de études andines, 21(2): 637- 649.

Pinard, M. 1993. Impact of stem harvesting on populations of Iriartea deltoidea (Palmae) in an Extractive Reserve in Acre, Brazil. Biotropica, 25(1): 2-14.

Piñero, D.; Martinez-Ramos, M.; Sarukhán, J. 1984. A population model of Astrocaryum mexicanum and a sensivity analysis of its finite rate of increase. Journal of Ecology, 72: 997-991.

Prance, G. T.; Rodrigues, W. A. ; Silva, M. F. 1976. Inventário florestal de 1 hectare de mata de Terra firme, $\mathrm{km} 30$ da estrada de Manaus-Itacoatiara. Acta Amazônica, 6(1): 9-35.
Radam Brasil. 1976 Folha SC.19 Rio Branco. Ministerio das Minas e Energia, Departamento Nacional da Produção Mineral, Projeto Radam Brasil, Rio de Janeiro.

Reis, A. 1995. Dispersão de sementes de Euterpe edulis Martius (Palmae) em uma Floresta Ombrófila Densa Montana da encosta atlântica em Blumenau, SC. Tese de Doutorado. UNICAMP. Campinas, $154 \mathrm{p}$.

Ros-Tonen, M.; Dijkman, W.; Bueren, E. L. 1995. Commercial and sustainable extraction of Non-Timber forest products. Towards a policy and management oriented research strategy. The Tropenbos Foundation. Wageningen, the Netherlands. Theme Strategy. Paper number 1. 43p.

Sarukhán, J.; Martinez -Ramos, M; Pinero, D. 1984. The analysis of demographic variability at the individual level and its population consequences. In: Dirzo, R.; Sarukhán, J. (Eds.). Perspectives on plant population ecology. Sinauer Massachusetts. 478p.

Secretaria de Comércio Exterior (SECEX). 1998. www.mdic.gov.br/ comext/default.htm

Silva- Matos, D. M. 1995. Population Ecology of Euterpe edulis Mart. (Palmae). Tese de Doutorado. University of East Anglia, Norwich. England. 187p.

Swaine, M. D.; Lieberman, D.; Putz, F. E. 1987. The dynamics of tree populations in tropical forest: A review. Journal of Tropical Ecology 3: 359-366.

Veloso, H. P.; Rangel, F.A.L.R.; Lima, J. C. A. 1991. Classificação da vegetação brasileira, adaptada a um sistema universal. IBGE, Rio de Janeiro. 124p.

Zuidema, P. A.; Boot, R. G. A. 2000. Demographic constraints to sustainable palm heart extraction from a sub-canopy palm in Bolivia. In: Zuidema, P. A. (Ed.) Demography of exploited tree species in the Bolivian Amazon. Universiteit Utrecht $\mathrm{e}$ Programa de Manejo de bosques de la Amazônia boliviana. Riberalta, Bolívia. p. 53-79.

Wallace, R. H. 1999. A study of Açaí (Euterpe precatoria) Bacaba (Oenocarpus mapora) and Pataúa (Oenocarpus bataua) in the Extractive Reserve Chico Mendes and the city of Rio Branco, Acre, Brazil. Relatório de pesquisa. The Rainforest Alliance Kleinhans Fellowship. Rio Branco, AC. 71p.7

\section{RECEBIDO EM 10/06/2003 ACEITO EM 12/05/2004}

